\title{
Prevalence of hypothyroidism amongst pregnant women: a study done in rural set up
}

\section{Nancy S. Pillai*, Jemela Bennett}

Department of Obstetrics and Gynecology, Tertiary Centre, Kerala, India

Received: 09 February 2018

Accepted: 07 March 2018

\section{*Correspondence:}

Dr. Nancy S. Pillai,

E-mail: nancy_pillai@yahoo.co.in

Copyright: (C) the author(s), publisher and licensee Medip Academy. This is an open-access article distributed under the terms of the Creative Commons Attribution Non-Commercial License, which permits unrestricted non-commercial use, distribution, and reproduction in any medium, provided the original work is properly cited.

\begin{abstract}
Background: Thyroid disorders are the commonest endocrine disorders affecting women of reproductive age group. The most frequent thyroid disorder in pregnancy is maternal hypothyroidism. During early pregnancy the foetus is totally dependent on maternal thyroid hormone supply. Thyroid hormone is critical for foetal brain and intellectual development and some preventable conditions like abruption, pre-eclampsia etc. which produce morbidity and pose special risk for pregnancy and the developing foetus.

Methods: All subjects enrolled in the study as per the inclusion criteria will be subjected to a detailed history and clinical examination using a predesigned proforma. A serum TSH value will be sent in 1st trimester between 6-10 weeks period of gestation for all pregnant women.

Results: The prevalence of thyroid dysfunction in pregnancy was $10.8 \%$ with hypothyroidism being $9.2 \%$, out of which $8.5 \%$ were cases of subclinical hypothyroidism and $0.7 \%$ were cases of overt hypothyroidism. On assessing the risk factors for developing thyroid dysfunction in pregnancy, increases in incidence were seen with maternal age and increasing BMI, both of which were statistically significant.

Conclusions: This study showed an increased prevalence of hypothyroidism in pregnancy recommending a need for universal screening for all pregnant women in the first trimester itself. This study aims at validating the efficacy of the above-mentioned screening.
\end{abstract}

Keywords: Hypothyroidism in pregnancy, Prevalence, Screening

\section{INTRODUCTION}

Thyroid dysfunction during pregnancy has been an important area of research due to its imminent impact on maternal and foetal outcome. It has long been recognized that maternal thyroid hormone excess or deficiency can influence the outcome for mother and foetus as well as interfere with ovulation and fertility., ${ }^{1,2}$

The prevalence of hypothyroidism in pregnancy is around $2.5 \%$ according to western literature. There are few reports of prevalence of hypothyroidism during pregnancy from India with rates ranging from $4.8 \%$ to $11 \% .^{3,4}$

Thyroid dysfunction during pregnancy is associated with adverse maternal complications like miscarriages, anaemia complicating pregnancy, pre-eclampsia, abruptio-placentae, postpartum haemorrhage and foetal complications like premature birth, low birth weight ,increased neo-natal respiratory distress .Maternal and foetal hypothyroidism can also result in irreversible brain damage with mental retardation and neurologic abnormalities which justifies screening for thyroid 
dysfunction during early pregnancy with interventional levothyroxine therapy for thyroid hypofunction. ${ }^{5-10}$

Pregnancy results in a number of important physiological and hormonal changes that alter thyroid function mainly due to the influence of two main hormone; human chronic gonadotropin (HCG) and estrogen. ${ }^{1,11}$ Thyroid dysfunction is often overlooked in pregnancy because of the non-specific symptoms and the hyper metabolic state of pregnancy. ${ }^{12}$

Serum thyroid stimulating hormone concentration is the initial and most reliable test for assessing thyroid function in pregnancy. ${ }^{13}$ Due to the dynamic changes during pregnancy, use of trimester specific normal ranges of TSH is recommended. Hence the Endocrine Society guidelines recommend $2.5 \mathrm{mIU} / \mathrm{L}$ as the normal upper limit of TSH in the first trimester. ${ }^{14} \mathrm{~A}$ rise in serum TBG concentration and its half-life induced by oestrogen also occurs in first trimester and is sustained at this high level throughout pregnancy. ${ }^{15}$ As a consequence, the serum total $\mathrm{T}_{4}$ and $\mathrm{T}_{3}$ concentrations increases by $5 \%$ but circulating Free or unbound $\mathrm{T}_{4}$ and $\mathrm{T}_{3}$ concentrations are largely unchanged and therefore may be used for assessment of thyroid status in pregnancy.

Hypothyroidism denotes deficient production of thyroid hormones by the thyroid gland and can be primaryabnormality in the thyroid gland itself or secondary/central-as a result of hypothalamic or pituitary disease. Overt hypothyroidism $(\mathrm{OH})$ is that grade of primary hypothyroidism which is associated with an increase in serum TSH, usually above $10 \mathrm{mIU} / \mathrm{L}$ along with a decreased concentration of thyroxin, as a result of negative feedback. Sub-clinical hypothyroidism $(\mathrm{SH})$ refers to an increase in serum TSH (T4), usually between 4-10mIU/L associated with a normal concentration of serum thyroxin (T4) and tri-iodothyronine (T3).

Current guidelines for screening of thyroid dysfunction during pregnancy differ between an aggressive case finding approach versus universal screening. ${ }^{16,17}$ Due to uncertainty of universal iodine sufficiency and higher incidence of thyroid antibody positivity in India, the Indian Thyroid Society recommendations of universal screening for hypothyroidism during pregnancy is more advisable for Indian population. ${ }^{18}$

When the Endocrine Society guidelines were used for diagnosis, a much larger prevalence of hypothyroidism, especially subclinical hypothyroidism has been recognized with marked variation between different ethnic groups. ${ }^{19-21}$ In the published literatures north Indian women appear to have the highest rate of subclinical hypothyroidism in the first trimester of pregnancy. ${ }^{4,22,23}$

Majority of the pregnant women with overt hypothyroidism and good number with subclinical hypothyroidism who were studied had positive Anti
Thyroid Peroxidase (TPO) antibody suggesting autoimmunity as one of the important causes of hypothyroidism..$^{3,24}$

There is a paucity of studies analysing the demographic and other variables associated with hypothyroidism in pregnancy, probably due to the physiological changes in thyroid function during pregnancy. The mean age of presentation of hypothyroidism in pregnancy in Indian studies was lower as compared to western studies. ${ }^{25,26}$ However in general population the incidence of thyroid dysfunction has been reported to increase with advancing age. $^{27,28}$

Hypothyroidism has been associated with a positive family history of autoimmune thyroiditis and also with a positive family history of other autoimmune disorders. ${ }^{29}$

Several studies have shown BMI to be positively correlated to serum TSH and negatively to serum free T4 (FT4) in women with overt hypothyroidism. ${ }^{30}$ No relation has however been demonstrated between BMI and thyroid function in euthyroid individuals or patients with subclinical hypothyroidism. ${ }^{31,32}$

With the proposed study we intend to emphasize the need for universal screening as suggested by the Indian thyroid society.

\section{METHODS}

The study was conducted at a rural health centre of Dr. Somervell Memorial Medical College, Karakonam, Kerala, in the department of obstetrics and gynecology after obtaining clearance from institutional ethical committee and consent from the study subjects. A prospective observational study was conducted for two years between 2013 to 2015 .

All consecutive pregnant women having their antenatal check -ups at the hospital. From the previous studies prevalence of hypothyroidism amongst pregnant women in India ranges from 4.8-11\% (78) according to which sample size is to be calculated.

Sample size $=4 \mathrm{PQ} / \mathrm{D} 2=4 \times 11 \times 89 / 22=979$

Where $\mathrm{P}=$ Prevalence of hypothyroidism in pregnant women; Q=100-P; Expected prevalence-11; D=Precision Precision- $2 \%$

\section{Inclusion criteria}

- $\quad$ Primi and multigravida belonging to any age group

- $\quad$ Singleton pregnancy

- Patients in the first trimester

\section{Exclusion criteria}

- Patients with pre-gestational hypothyroidism. 
- Multiple pregnancy

- Gestational trophoblastic disease.

All subjects enrolled in the study as per the inclusion criteria will be subjected to a detailed history and clinical examination using a predesigned proforma.

A serum TSH value will be sent in 1 st trimester between 6-10 weeks period of gestation for all pregnant women. Trimester specific normal range of serum TSH for the first trimester is $0.1-2.5 \mathrm{mIU} / \mathrm{L} .{ }^{14}$ Subjects with Serum TSH value above the normal range will be considered for estimation of freeT4 level to classify as subclinical or overt hypothyroidism. Elevated TSH with a low fT4 suggests overt hypothyroidism and elevated TSH with a normal fT4 suggests subclinical hypothyroidism. A TSH value above $10 \mathrm{mIU} / \mathrm{L}$ will be considered as overt hypothyroid.

\section{Statistical analysis}

Prevalence of hypothyroidism in pregnancy will be assessed using descriptive method.

Outcome variables of Age and BMI will be compared according to thyroid status using t-test and TSH and fT4 will be analyses for association with thyroid status using 'Chi Square' test. A p value of less than 0.05 was considered statistically significant.

\section{RESULTS}

A total 1000 subjects were enrolled in the study as per the inclusion criteria. A serum TSH value was sent in $1^{\text {st }}$ trimester between 6-10 weeks period of gestation for all pregnant women. Trimester specific normal range of serum TSH for the first trimester was considered for detecting those with thyroid dysfunction. The estimation of free T4 levels were done to reclassify those with thyroid dysfunction as subclinical or overt hypothyroidism.

Elevated TSH with a low fT4 suggests overt hypothyroidism and elevated TSH with a normal fT4 suggests subclinical hypothyroidism. A TSH value above 10mIU/L will be considered as overt hypothyroid.

Table 1: Distribution of study population according to thyroid status.

\begin{tabular}{|lll|}
\hline Thyroid status & Number & Percentage \\
\hline Euthyroid & 892 & $89.2 \%$ \\
\hline Thyroid dysfunction & 108 & $10.8 \%$ \\
\hline
\end{tabular}

Of the 1000 consecutive antenatal women attending OP in the first trimester who were evaluated for thyroid status,108 (10.8\%) had thyroid dysfunction and 892 $(89.2 \%)$ were euthyroid. Hence the prevalence of thyroid dysfunction in the study is $10.8 \%$ (Table 1 ).
Table 2: Distribution of study population according to subtypes.

\begin{tabular}{|lll|}
\hline Subtypes-of thyroid dysfunction & Number & $\%$ \\
\hline Euthyroid & 892 & $89.2 \%$ \\
\hline Overt hypothyroid & 7 & $0.7 \%$ \\
\hline Subclinical hypothyroid & 85 & $8.5 \%$ \\
\hline Subclinical hyperthyroid & 16 & $1.6 \%$ \\
\hline Overt hyperthyroid & 0 & 0 \\
\hline
\end{tabular}

The women with thyroid dysfunction were regrouped according to the TSH values as to the type of thyroid dysfunction they had. Out of the 108 women who were detected to have thyroid dysfunction, 85 (8.5\%) had subclinical hypothyroidism, $7(0.7 \%)$ had overt hypothyroidism, $16 \quad(1.6 \%)$ had subclinical hyperthyroidism and no cases of overt hyperthyroidism were noted (Table 2).

Table 3: Age wise distribution of screened population.

\begin{tabular}{|c|c|c|c|c|c|}
\hline \multirow[t]{2}{*}{ Age } & \multicolumn{2}{|c|}{ Euthyroid } & \multicolumn{2}{|c|}{$\begin{array}{l}\text { Thyroid } \\
\text { dysfunction }\end{array}$} & $\begin{array}{l}P \\
\text { value }\end{array}$ \\
\hline & No. & $\%$ & No. & $\%$ & \multirow{6}{*}{0.019} \\
\hline$\leq 20$ & 60 & 83.3 & 12 & 16.67 & \\
\hline $21-25$ & 345 & 92.24 & 29 & 7.75 & \\
\hline $26-30$ & 327 & 88.86 & 41 & 11.14 & \\
\hline $31-35$ & 123 & 89.05 & 14 & 10.21 & \\
\hline$\geq 36$ & 37 & 76.71 & 12 & 23.29 & \\
\hline
\end{tabular}

The age of the screened population was compared to note the prevalence of thyroid dysfunction with age. The mean age of women was 26.66years. It was observed that as the age advances there is increased risk of developing thyroid dysfunction in pregnancy. This observation is statistically significant ( $\mathrm{p}$ value 0.019 ) (Table 3 ).

Table 4: Distribution of thyroid dysfunction according to BMI.

\begin{tabular}{|c|c|c|c|c|c|}
\hline \multirow[t]{2}{*}{ BMI } & \multicolumn{2}{|c|}{ Euthyroid } & \multicolumn{2}{|c|}{$\begin{array}{l}\text { Thyroid } \\
\text { dysfunction }\end{array}$} & $\begin{array}{l}P \\
\text { value }\end{array}$ \\
\hline & No. & $\%$ & No. & $\%$ & \multirow{5}{*}{0.015} \\
\hline$\leq 18.5$ & 28 & 3.13 & 5 & 4.43 & \\
\hline $18.6-24.9$ & 677 & 75.93 & 70 & 64.56 & \\
\hline $25-29.9$ & 156 & 17.51 & 29 & 27.22 & \\
\hline$\geq 30$ & 31 & 3.43 & 4 & 3.8 & \\
\hline
\end{tabular}

The BMI of the screened population in the first trimester was compared to note the correlation with thyroid dysfunction. It was noted that $27.22 \%$ of patients with thyroid dysfunction were with BMI 25-29.9 (over weight) and $3.8 \%$ were with BMI 30 or more(obese) but only $17.51 \%$ of euthyroid were with BMI $25-2.9$ and $3.43 \%$ were with BMI 30 or more. An increased risk of thyroid dysfunction in pregnancy is noted as the BMI increases. The $\mathrm{p}$-value was statistically significant $(\mathrm{p}=0.015)$ (Table 4). 


\section{DISCUSSION}

Thyroid disorders are one of the most common endocrine disorders in women during pregnancy and are associated with adverse maternal and foetal outcome. Universal screening at the first antenatal visit helps in detecting thyroid dysfunction in pregnancy. Preferably preconceptional screening for thyroid dysfunction is ideal as any hypothyroid state can be corrected before attempting pregnancy.

This clinical study to know the prevalence of thyroid dysfunction in pregnancy and to assess its association with age and BMI was conducted in the department of obstetrics and gynaecology in a rural health centre of Dr. Somervell Memorial Medical College, Karakonam during the time period October 2013 to October 2015. During this period 1000 consecutive antenatal women attending $\mathrm{OP}$ in the first trimester were evaluated for thyroid status.

\section{Prevalence of hypothyroidism}

The prevalence of thyroid dysfunction in the present study was $10.8 \%$, of which hypothyroidism constituted 9.2\%, with sub-clinical hypothyroidism constituting $8.5 \%$ and overt hypothyroidism accounting for $0.7 \%$ and subclinical hyperthyroidism was $1.6 \%$.

The prevalence of hypothyroidism in the present study was comparable to the study by Sahu et al who reported a prevalence of hypothyroidism of $12.7 \%$ with overt and subclinical hypothyroidism to be $4.58 \%$ and $6.47 \% .^{4}$ Dhanwal et al from Delhi in 2013 reported a prevalence of hypothyroidism as $14.3 \%$, with sub-clinical hypothyroidism constituting $9 \%$ and overt hypothyroidism constituting $3 \% .^{22}$ Ajmani et al also observed a prevalence of hypothyroidism of $13.5 \%$ with subclinical and overt hypothyroidism accounting for $9 \%$ and $3 \%$ respectively, which was comparable to present study. ${ }^{33}$ A study done in 2011 by Wang et al noted a prevalence of thyroid dysfunction of $10.2 \%$, with subclinical hypothyroidism being $7.2 \%$ and that of overt hypothyroidism accounting for $0.3 \% .^{34}$

\section{Association of thyroid dysfunction in pregnancy with age}

There is a paucity of studies analysing the association of age and BMI with hypothyroidism in pregnancy, probably due to the physiological changes in thyroid function during pregnancy.

The guidelines of American Thyroid Association from 2011 included age over 30years as one of the risk factors for hypothyroidism in pregnancy.

The mean age of women in this study was 26.66years $(\mathrm{SD}=4.00)$ and in this study the occurrence of thyroid dysfunction in pregnancy has showed an increasing trend as the maternal age advances $(\mathrm{p}=0.019)$.
The studies done by Vaidhya B et al in 2007 showed a lower age compared to the Western studies. ${ }^{25}$ This is due to the early marriage and conception prevalent in our area.

A study by Ajmani et al has also shown an increased occurrence of thyroid dysfunction with advanced maternal age ${ }^{33}$ Potlukova et al did a cross-sectional study amongst antenatal women and found no significant association between age and serum TSH suppression or elevation. ${ }^{35}$ However, in general population the incidence of thyroid dysfunction has been reported to increase with advancing age. ${ }^{27,28}$

\section{Association of thyroid dysfunction in pregnancy with BMI}

In this study $27.72 \%$ population having thyroid dysfunction were with BMI $25-29.9 \mathrm{~kg} / \mathrm{m}^{2}$ (over weight) and $3.8 \%$ were with BMI $30 \mathrm{~kg} / \mathrm{m}^{2}$ or more (obese) but only $17.51 \%$ of euthyroid were with BMI $25-29.9 \mathrm{~kg} / \mathrm{m}^{2}$ and $3.43 \%$ were with BMI $30 \mathrm{~kg} / \mathrm{m}^{2}$ or more. An increased risk of thyroid disorder in pregnancy was noted as BMI increases. This was statistically significant $(\mathrm{p}=0.015)$.

A study by Ajmani et al also showed an increase in incidence of thyroid dysfunction with BMI. ${ }^{33}$ Knudsen N et al also did a study to investigate the association between thyroid function and BMI and found a positive association between BMI and serum TSH and a negative association between BMI and serum free T4 levels. ${ }^{34}$ Figueroa et al also studied the association between TSH levels and BMI and a higher prevalence of subclinical hypothyroidism was observed in those with increased BMI. ${ }^{32}$

\section{CONCLUSION}

Thyroid dysfunction in pregnancy is often associated with maternal and foetal complications.1000 women were included in the present study. The level of serum TSH was assessed in the first trimester. The prevalence of thyroid dysfunction in pregnancy was $10.8 \%$ with hypothyroidism being $9.2 \%$, out of which $8.5 \%$ were cases of subclinical hypothyroidism and $0.7 \%$ were cases of overt hypothyroidism.

On assessing the risk factors for developing thyroid dysfunction in pregnancy, increases in incidence were seen with maternal age and increasing BMI, both of which were statistically significant. This study shows an increased prevalence of hypothyroidism in pregnancy recommending a need for universal screening for all pregnant women in the first trimester itself.

\section{ACKNOWLEDGMENTS}

Authors would like to thank Dr. Mary Padmini Jasper, Dr. Somervell, for their able guidance and continuous 
encouragement at every step. Author would also want to thank Mr. Reni Alphonse for his continuous support at every step. Author would also want to thank Mr. Pramod Thomas for his valuable suggestions and guidance.

Funding: No funding sources Conflict of interest: None declared

Ethical approval: The study was approved by the Institutional Ethics Committee

\section{REFERENCES}

1. Glinoer D. The regulation of thyroid function in pregnancy: pathways of endocrine adaptation from physiology to pathology. Endocr Rev. 1997;18:40433.

2. Casey BM, Leveno KJ. Thyroid diseases in pregnancy. Obstet Gynecol. 2006;108:1283-92.

3. Jagtap NV. Prevalence and impact of thyroid disorders on maternal outcome in Asian-Indian pregnant women. J Thyroid Res. 2011;429097.

4. Sahu MT, Das V. Overt and subclinical thyroid dysfunction among Indian pregnant women and its effect on maternal and foetal outcome. Arch Gynecol Obstet. 2010;2812:215-20.

5. Davis LE, Leveno KJ, Cunningham FG. Hypothyroidism complicating pregnancy. Obstet Gynecol. 1988;72(1):108-s12.

6. Leung AS, Millar LK, Koonings PP, Montoro M, Mestman JH. Perinatal outcome in hypothyroid pregnancies. Obstet Gynecol. 1993;81(3):349-53.

7. Allan WC, Haddow JE, Palomaki GE. Maternal thyroid deficiency and pregnancy complications: implications for population screening. J Med Screen. 2000;7(3):127-30.

8. Abalovich M, Gutierrez S, Alcaraz G, Maccallini G, Garcia A, Levalle O. Overt and subclinical hypothyroidism complicating pregnancy. Thyroid. 2002;12(1):63-8.

9. Casey BM, Dashe JS, Wells CE. Subclinical hypothyroidism and pregnancy outcomes. Obstet Gynecol. 2005;105(2):239-45.

10. Negro R, Schwartz A. Increased pregnancy loss rate in thyroid antibody negative women with TSH levels between 2.5 and 5 in the first trimester of pregnancy. J Clin Endocrinol Metab. 2010;95:E44-8.

11. Van-Raaij JM. Energy requirements of pregnancy in the Netherlands Lancet. 1987;2:953-5.

12. Le Bean SO, Mandal SJ. Thyroid disorders during pregnancy. Endocrinal Metab Clin N Am. 2006;35:117-36.

13. Glinoer D, Spencer CA. Serum TSH determinations in pregnancy: how, when and why?. Nature Rev Endocrinol. 2010;6(9):526-9.

14. Garber JR, Cobin RH, Gharib H. Clinical practice guidelines for hypothyroidism in adults: cosponsored by American Association of Clinical Endocrinologists and the American Thyroid Association. Endoc Pract. 2012;11:1-207.
15. Ecker JL, Musci TJ. Treatment of thyroid disease in pregnancy. Presc Preg. 1997;24:575-89.

16. De Groot L, Abalovich M, Alexander EK. Management of thyroid dysfunction during pregnancy and postpartum: an Endocrine Society clinical practice guideline. J Clinic Endocrinol Metab. 2012;97(8):2543-65.

17. Stagnaro-Green A, Abalovich M, Alexander E. Guidelines of the American Thyroid Association for the diagnosis and management of thyroid disease during pregnancy and postpartum. Thyroid. 2011;21(10).

18. Clinical Practice Guidelines New Delhi: Elsevier; 2012. Indian Thyroid Society guidelines for management of thyroid dysfunction during pregnancy.

19. Atomare M, Vignesa LA. High prevalence of thyroid dysfunction in pregnant women. $\mathrm{J}$ Endocrinal Invest. 2013;36:407-11.

20. Blall AJ, Nakamoto JM. National status of testing for hypothyroidism during pregnancy and postpartum. J Clin Endocrinal Metab. 2012;97:777-84.

21. Mosso L, Martínez A, Rojas MP, Margozzini P, Solari S, Lyng T, et al. Frequency of subclinical thyroid problems among women during the first trimester of pregnancy. Revista medica de Chile. 2012 Nov;140(11):1401-8.

22. Dhanwal DK, Prasad S, Agarwal AK, Dixit V, Banerjee AK. High prevalence of subclinical hypothyroidism during first trimester of pregnancy in North India. Indian $\mathbf{J}$ Endocrinol Metab. 2013;17(2):281.

23. Goel P, Kaur J, Saha PK, Tandon R, Devi L. Prevalence, associated risk factors and effects of hypothyroidism in pregnancy: a study from north India. Gynecologic Obstet Invest. 2012;74(2):89-94.

24. Gayathri R, Lavanya S, Raghavan K. Subclinical Hypothyroidism and Autoimmune Thyroiditis in Pregnancy: A study in South Indian Subjects. JAPI. 2009;57:691-3.

25. Vaidya B, Anthony S, Bilous M, Shields B, Drury J, Hutchison S, Bilous R. Detection of thyroid dysfunction in early pregnancy: universal screening or targeted high-risk case finding?. J Clinic Endocrinol Metab. 2007 Jan 1;92(1):203-7.

26. Negro R, Formoso G. Levothyroxin treatment in Euthyroid pregnant women with auto immune thyroid immune disease: effects on obstetrical complications. J Clin Endocrinol Metab. 2006;91(7):2587-91.

27. Tunbridge WM, Evered DC. The spectrum of thyroid disease in a community: The Wickham survey. Clin Endocrinol. 1997;7:481-93.

28. Wang C, Crap LM. The epidemiology of thyroid disease and implications for screening. Endocrinol Metab Clin North Am. 1997;26:189-218.

29. Saikh MG, Anderson JM. Transient neonatal hypothyroidism due to maternal vegan diet. J Pediatr Endocrinol Metab. 2003;16:111-3. 
30. Knudsen N, Laurberg P, Rasmussen LB, Bülow I, Perrild H, Ovesen L, Jørgensen T. Small differences in thyroid function may be important for body mass index and the occurrence of obesity in the population. J Clinic Endocrinol Metab. 2005;90(7):4019-24.

31. Manji N, Boelaert K, Sheppard MC, Holder RL, Gough SC, Franklyn JA. Lack of association between serum TSH or free T4 and body mass index in euthyroid subjects. Clinic Endocrinol. 2006;64(2):125-8.

32. Figueroa $B$, Vélez $H$, Irizarry-Ramirez $M$. Association of thyroid-stimulating hormone levels and body mass index in overweight Hispanics in Puerto Rico. Ethn Dis. 2008;18:S2151-4.

33. Ajmani SN, Aggarwal D, Bhatia P, Sharma M, Sarabhai V, Paul M. Prevalence of overt and subclinical thyroid dysfunction among pregnant women and its effect on maternal and fetal outcome. J Obstet Gynecol India. 2014;64(2):105-10.

34. Wang W, Teng W, Shan Z. The prevalence of thyroid disorder during early pregnancy in China: the benefits of universal screening in the first trimester of pregnancy. Eur J Endocrinol. 2011;164(2):263.

35. Potlukova E, Potluka O, Jiskra J, Limanova Z, Telicka Z, Bartakova J, et al. Is age a risk factor for hypothyroidism in pregnancy? An analysis of 5223 pregnant women. J Clinic Endocrinol Metab. 2012;97(6):1945-52.

Cite this article as: Pillai NS, Bennett J. Prevalence of hypothyroidism amongst pregnant women: a study done in rural set up. Int J Reprod Contracept Obstet Gynecol 2018;7:1586-91. 